\title{
Measurement of particulate matter 2.5 in surgical smoke and its health hazards
}

\author{
$\mathrm{Kae} \mathrm{Okoshi}^{1,2} \cdot \mathrm{Koya} \mathrm{Hida}^{3} \cdot \mathrm{Koichi} \mathrm{Kinoshita}^{1} \cdot$ Toshitaka Morishima $^{4} \cdot$ Yoshie Nagai $^{5} \cdot$ Yasuko Tomizawa $^{6}$. \\ Kyoko Yorozuya $^{7} \cdot$ Takehiro Nishida $^{8} \cdot$ Hisako Matsumoto ${ }^{9} \cdot$ Hiroshi Yamato $^{10}$
}

Received: 22 October 2021 / Accepted: 25 December 2021 / Published online: 21 February 2022

(c) The Author(s) under exclusive licence to Springer Nature Singapore Pte Ltd. 2022, corrected publication 2022

\begin{abstract}
Purpose Surgical smoke is generated during the cauterization, coagulation, and incision of biological tissues by electrocautery, ultrasonic coagulation, incising devices, and lasers. Surgical smoke comprises water, water vapor, steam, and some particulate matter, including bacteria, viruses, cell fragments, and volatile organic compounds, which can pose health risks to the operating room personnel. In this study, we measured the concentration of particulate matter 2.5 (particles with a diameter of $\leq 2.5 \mu \mathrm{m}$ ) in surgical smoke.

Methods We used digital dust counters for real-time monitoring of particulate matter 2.5 generated intraoperatively in breast and gastrointestinal surgeries performed at our hospitals between 2019 and 2020.

Results Concentrations of particulate matter 2.5 were measured in surgical smoke generated when performing 14 different surgeries. Immediately after electrocautery, the concentration of particulate matter 2.5 increased to $2258 \mu \mathrm{g} / \mathrm{m}^{3}$ and then, when we stopped using the devices, it decreased rapidly to the initial levels. Interestingly, the concentrations increased after each intermittent electrocautery procedure. Higher concentrations of particulate matter 2.5 were observed during breast surgeries than during laparoscopic procedures.

Conclusion Surgical smoke poses potential health risks to operating room personnel by contaminating their breathing zone with high concentrations of particulate matter 2.5. A local exhaust ventilation system is needed to reduce exposure.
\end{abstract}

Keywords COVID-19 $\cdot$ Cautery $\cdot$ Laparoscopy $\cdot$ Particulate matter $\cdot$ Surgical smoke

Kae Okoshi

kae_md@kuhp.kyoto-u.ac.jp

1 Department of Surgery, Japan Baptist Hospital, 47 Yamonomoto-cho, Kitashirakawa, Sakyo-ku, Kyoto 606-8273, Japan

2 Research Center for Science, Technology and Social Communication in Next Generation, Doshisha University, Kyotanabe, Japan

3 Department of Surgery, Kyoto University Hospital, Kyoto, Japan

4 Cancer Control Center, Osaka International Cancer Institute, Osaka, Japan

5 Department of Anesthesiology, Kawasaki Municipal Ida Hospital, Kawasaki, Japan
6 Department of Cardiovascular Surgery, Tokyo Women's Medical University, Tokyo, Japan

7 Department of Surgery, Kawasaki Municipal Hospital, Kawasaki, Japan

8 Department of Anesthesiology, Masuda Red Cross Hospital, Masuda, Japan

9 Department of Respiratory Medicine and Allergology, Kindai University Hospital, Osakasayama, Japan

10 Department of Health Development, Institute of Industrial Ecological Sciences, University of Occupational and Environmental Health, Japan, Kitakyushu, Japan 


\section{Introduction}

Surgical smoke, comprising water, water vapor, and particulate matter, is generated by high-energy devices, namely electrocautery and ultrasonic coagulation incision devices, during cauterization, coagulation, and incision of biological tissues. The visible white plume consists primarily of water and fine particles containing tissue, cell fragments, and volatile chemicals. In some cases, it may also contain viruses such as human papillomavirus (HPV) and hepatitis B virus (HBV), bacteria, and other pathogens [1]. Kwak et al. [2] reported the presence of HBV deoxyribonucleic acid (DNA) in the surgical smoke, which was emitted during robotic or laparoscopic surgery in 10 of 11 patients with positive HBV antigen. Surgical procedures involving virus-infected organs may be associated with health risks for those in attendance in an operation room (OR). Cases of laryngeal papilloma were reported among surgeons and OR nurses in charge of laser treatment for condyloma caused by HPV [3, 4]. Furthermore, squamous cell carcinoma of the pharynx and tongue was reported among gynecologists involved in laser ablation and the loop electrosurgical excision procedure for early cervical cancer for many years [5]. Another study reported the presence of HPV DNA in surgical smoke emitted during the loop electrosurgical excision procedure surgery and in the nasal epithelial cells of the surgeons [6].

Surgical smoke also contains fine particulate matter and various harmful volatile organic compounds [7]. Fine particles, $0.5-3 \mu \mathrm{m}$ in size, can reach the peripheral bronchi [8] and cause bronchitis and asthma. Notably, volatile organic compounds can cause sick building syndrome [9].

Among the various substances contained in surgical smoke, our study focused on particulate matter $2.5\left(\mathrm{PM}_{2.5}\right)$, which refers to particles with a diameter of $\leq 2.5 \mu \mathrm{m}$. Exposure to $\mathrm{PM}_{2.5}$ is considered deleterious as it increases health risks for patients and clinicians. Therefore, we performed real-time monitoring of $\mathrm{PM}_{2.5}$ in the surgical smoke generated by electrocautery and ultrasonic coagulation incision devices in the OR. Using these results, we investigated the effects of $\mathrm{PM}_{2.5}$ on surgeons and OR personnel and the necessary countermeasures.

\section{Methods}

This prospective observational study focused on surgical procedures performed in our department between 2019 and 2020. We started our study with a planned case entry from September, 2019 to September, 2020. All participants provided informed consent prior to their inclusion in the
Table 1 Characteristics of the operating rooms analyzed in the study

\begin{tabular}{lllll}
\hline OR & $\begin{array}{l}\text { Area of OR } \\
\left(\mathrm{m}^{2}\right)\end{array}$ & $\begin{array}{l}\text { Differential } \\
\text { pressure }(\mathrm{Pa})\end{array}$ & $\begin{array}{l}\text { JIS (ISO) } \\
\text { class }\end{array}$ & $\begin{array}{l}\text { Designed air } \\
\text { change rate } \\
\text { (times/h) }\end{array}$ \\
\hline $\mathrm{A}$ & 31.2 & 0.5 & 7 & 62.6 \\
$\mathrm{~B}$ & 42.1 & 1.0 & 6 & 31.1 \\
\hline
\end{tabular}

$O R$ operating room, JIS Japanese Industrial Standards, ISO International Standards Organization
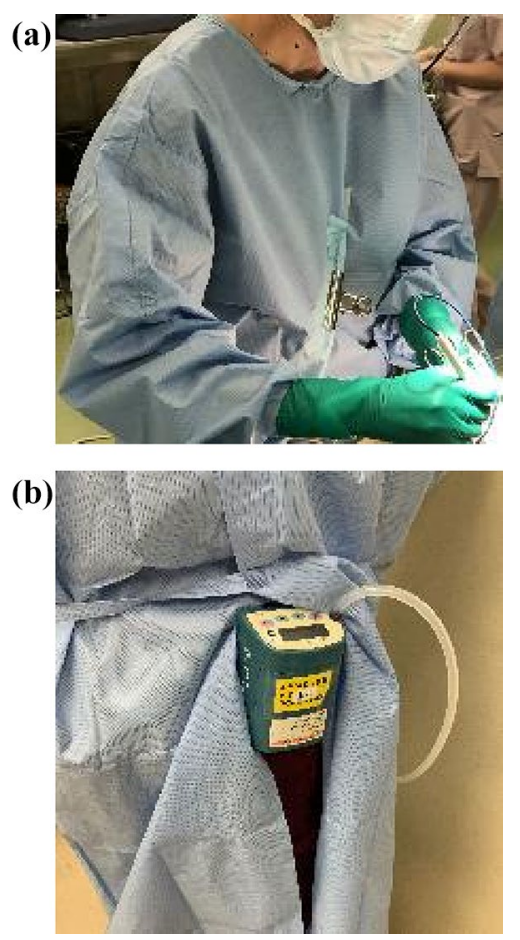

Fig. 1 Intraoperative real-time particulate matter $2.5\left(\mathrm{PM}_{2.5}\right)$ measurements. a The tube was affixed to the surgeon's anterior chest. b The digital dust meter was affixed to the surgeon's lower back

study, although because of the coronavirus disease 2019 (COVID-19) pandemic in 2020, the number of surgeries in this period was relatively low. Furthermore, surgeons and OR staff were compelled to use smoke exhaustion devices for surgical smoke control intraoperatively for infection control and ethical concerns. Therefore, we closed our case entry. Table 1 summarizes the features of the two operation rooms (A and B) that we used for the analysis.

We applied the method used by Yamato et al. to measure $\mathrm{PM}_{2.5}$ generated by smoking indoors [10]. A digital dust counter (SidePak AM510; TSI, Inc., Shoreview, MN, USA) was connected to a sterile silicone tube (length, $70 \mathrm{~cm}$; inner diameter, $5 \mathrm{~mm}$ ) affixed to the surgeon's anterior chest with tape (Fig. 1a). Another digital dust counter affixed to the back of the surgeon's surgical gown (Fig. 1b) started measuring $\mathrm{PM}_{2.5}$ simultaneously when the operation started, with 
measurements taken every $5 \mathrm{~s}$ until the surgery was completed. We attached another dust meter to the OR wall, $2 \mathrm{~m}$ away from the surgeon, and used the $\mathrm{PM}_{2.5}$ measurement as a control. The local exhaust ventilation (LEV) system was not used for open surgeries. We used Bonimed Switchpen (Muranaka Medical Instruments Co., Ltd., Osaka, Japan) and Opti4 (Covidien Japan Inc., Tokyo, Japan) for electrocauterization, Olympus SonoSurg (Olympus, Tokyo, Japan) as the ultrasonically activated device, and LigaSure (Covidien Japan Inc.) as the vessel-sealing system. Table 2 presents the types of devices used in each procedure. Furthermore, we used the intra-abdominal insufflation unit (UHI-4 ${ }^{\circledR}$, Olympus) for $\mathrm{CO}_{2}$ supply and exhaust for laparoscopic surgery, which had a wall suction evacuation system without filtration. The OR area, room differential pressure, International Standards Organization (ISO) class, and design ventilation frequency are presented in Table 1.

A suction tube was used by surgeons or assistants to aspirate the surgical smoke, as appropriate, for body surface surgery and laparotomy. Surgical smoke was not aspirated with a suction tube during extracorporeal procedures performed during laparoscopic surgery.

\section{Results}

Table 2 summarizes the characteristics of the 14 patients registered in this study. Highly elevated $\mathrm{PM}_{2.5}$ was observed during electrocautery for mastectomy (Fig. 2). During laparoscopic inguinal hernia repair (Fig. 3) and laparoscopic cholecystectomy (Fig. 4a), the concentration of $\mathrm{PM}_{2.5}$ increased in a spiky pattern when electrocautery was used to control bleeding during incision of the subcutaneous tissue and fascia. However, during intraperitoneal procedures, the $\mathrm{PM}_{2.5}$ concentration increased only slightly. In contrast, during the same surgery (laparoscopic cholecystectomy) without electrocautery for subcutaneous tissue or fasciotomy (Fig. 4b), no increase in $\mathrm{PM}_{2.5}$ was observed. During open surgery, the concentration of $\mathrm{PM}_{2.5}$ was very mildly elevated because the surgical smoke was aspirated with a suction tube (Fig. 5). Conversely, for laparoscopic colorectal resection, surgical smoke was not aspirated; therefore, high concentrations of $\mathrm{PM}_{2.5}$ were observed during incision and extracorporeal manipulation, without smoke evacuation using a suction tube (Fig. 6). During all operations, a dust meter placed $2 \mathrm{~m}$ from the surgeon showed a slight increase in $\mathrm{PM}_{2.5}$ levels (Figs. 2, 3, 4, 5 and 6).

\section{Discussion}

During the current COVID-19 pandemic, the Society of American Gastrointestinal and Endoscopic Surgeons and the European Association for Endoscopic Surgery issued recommendations regarding the use of smoke exhaust systems along with energy devices to prevent infection [11]. In response to these recommendations, the Japanese surgical associations jointly released similar recommendations [12]. In some countries and regions in Europe and the USA, mandatory countermeasures against surgical smoke had already

Table 2 Demographic and surgical characteristics of the study participants

\begin{tabular}{|c|c|c|c|c|c|c|c|c|c|}
\hline & Surgical procedure & Sex & $\begin{array}{l}\text { Age } \\
\text { (years) }\end{array}$ & $\begin{array}{l}\text { BMI } \\
\left(\mathrm{kg} / \mathrm{m}^{2}\right)\end{array}$ & $\begin{array}{l}\text { Blood loss } \\
(\mathrm{ml})\end{array}$ & $\begin{array}{l}\text { Operation time } \\
(\mathrm{min})\end{array}$ & $\begin{array}{l}\text { Maxi- } \\
\text { mum } \\
\mathrm{PM}_{2.5} \\
\left(\mu \mathrm{g} / \mathrm{m}^{3}\right)\end{array}$ & Devices & OR \\
\hline 1 & Total mastectomy + sentinel lymph node biopsy & $\mathrm{F}$ & 68 & 20.7 & 19 & 107 & 1331 & $\mathrm{E}$ & A \\
\hline 2 & Laparoscopic hernia repair & M & 48 & 26.5 & 3 & 114 & 100 & E; USAD (lap) & B \\
\hline 3 & Laparoscopic hernia repair & M & 34 & 21.7 & 9 & 127 & 82 & E; USAD (lap) & B \\
\hline 4 & Laparoscopic hernia repair & M & 58 & 20.5 & 8 & 81 & 965 & E; USAD (lap) & $\mathrm{B}$ \\
\hline 5 & Laparoscopic hernia repair & M & 80 & 18.6 & 5 & 90 & 543 & E; USAD (lap) & A \\
\hline 6 & Laparoscopic cholecystectomy & $\mathrm{F}$ & 64 & 23.9 & 5 & 95 & 176 & E; USAD (lap) & $\mathrm{B}$ \\
\hline 7 & Laparoscopic cholecystectomy & $\mathrm{F}$ & 56 & 19.1 & 5 & 127 & 14 & E; USAD (lap) & $\mathrm{B}$ \\
\hline 8 & Laparoscopic cholecystectomy & M & 70 & 24.1 & 10 & 53 & 367 & E; USAD (lap) & A \\
\hline 9 & Laparoscopic appendectomy & $\mathrm{F}$ & 54 & 22.6 & 9 & 38 & 69 & E; USAD (lap) & A \\
\hline 10 & Distal pancreatectomy & M & 65 & 27.1 & 1619 & 334 & 68 & E; USAD, VSS & B \\
\hline 11 & Total gastrectomy and cholecystectomy & M & 87 & 21.5 & 509 & 228 & 122 & E; USAD, VSS & B \\
\hline 12 & Laparoscopic right colectomy & M & 75 & 18.1 & 30 & 220 & 2258 & $\mathrm{E} ; \mathrm{E}+\mathrm{USAD}$ (lap) & $\mathrm{B}$ \\
\hline 13 & Laparoscopic right colectomy & $\mathrm{F}$ & 64 & 28.1 & 5 & 262 & 159 & $\mathrm{E} ; \mathrm{E}+\mathrm{USAD}$ (lap) & $\mathrm{B}$ \\
\hline 14 & Laparoscopic ileocecal resection & $\mathrm{F}$ & 56 & 24.4 & 8 & 189 & 1345 & $\mathrm{E} ; \mathrm{E}+\mathrm{USAD}$ (lap) & B \\
\hline
\end{tabular}

$B M I$ body mass index, $P M_{2.5}$ particulate matter $2.5, O R$ operating room, $F$ female, $M$ male, $E$ electrocautery, USAD ultrasonically activated device, VSS vessel-sealing system, lap laparoscopic 


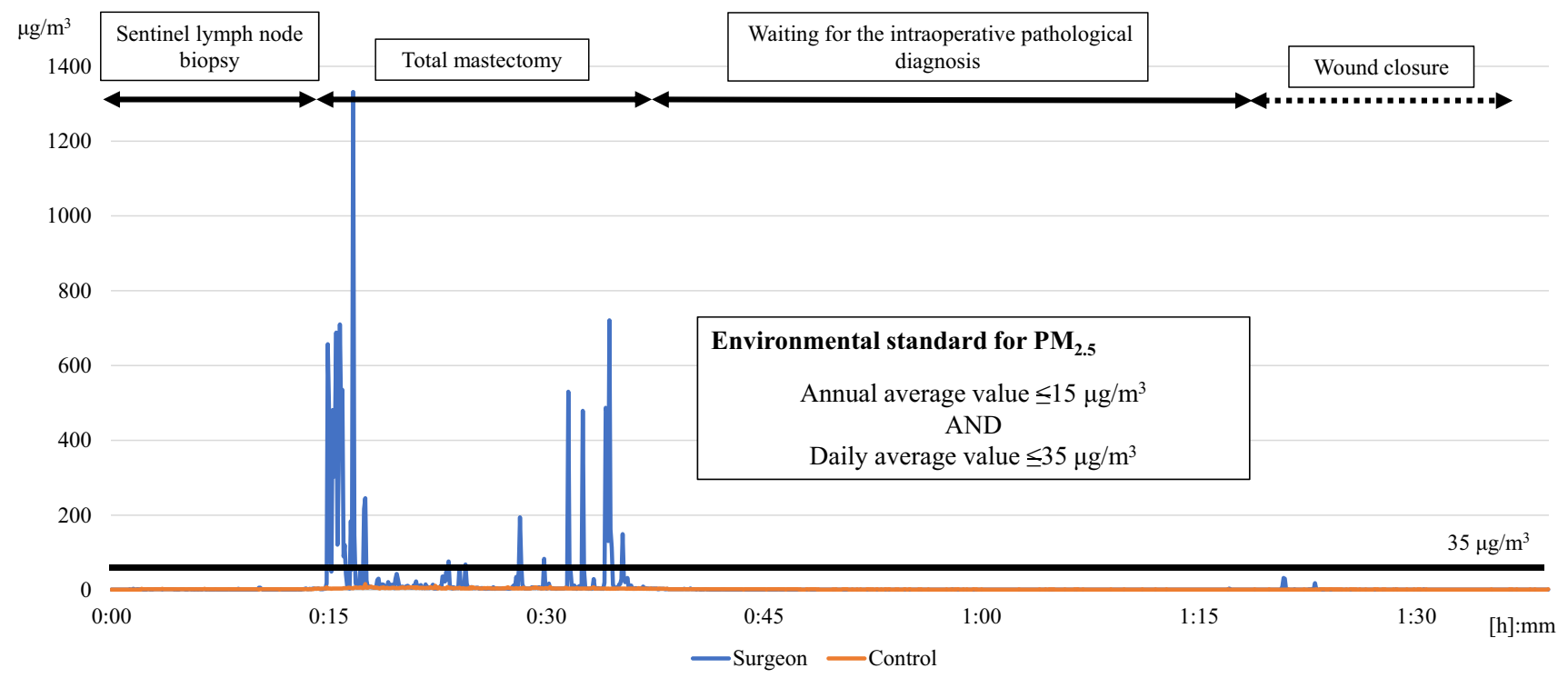

Fig. $2 \mathrm{PM}_{2.5}$ concentration during total mastectomy and sentinel lymph node biopsy (Patient 1). When using electrocautery, the $\mathrm{PM}_{2.5}$ concentration was significantly higher than the environmental stand- ard. Surgeon: $\mathrm{PM}_{2.5}$ measured at the anterior chest of the surgeon. Control: $\mathrm{PM}_{2.5}$ measured on the operating room wall, $2 \mathrm{~m}$ from the surgeon. $P M_{2.5}$ particulate matter 2.5

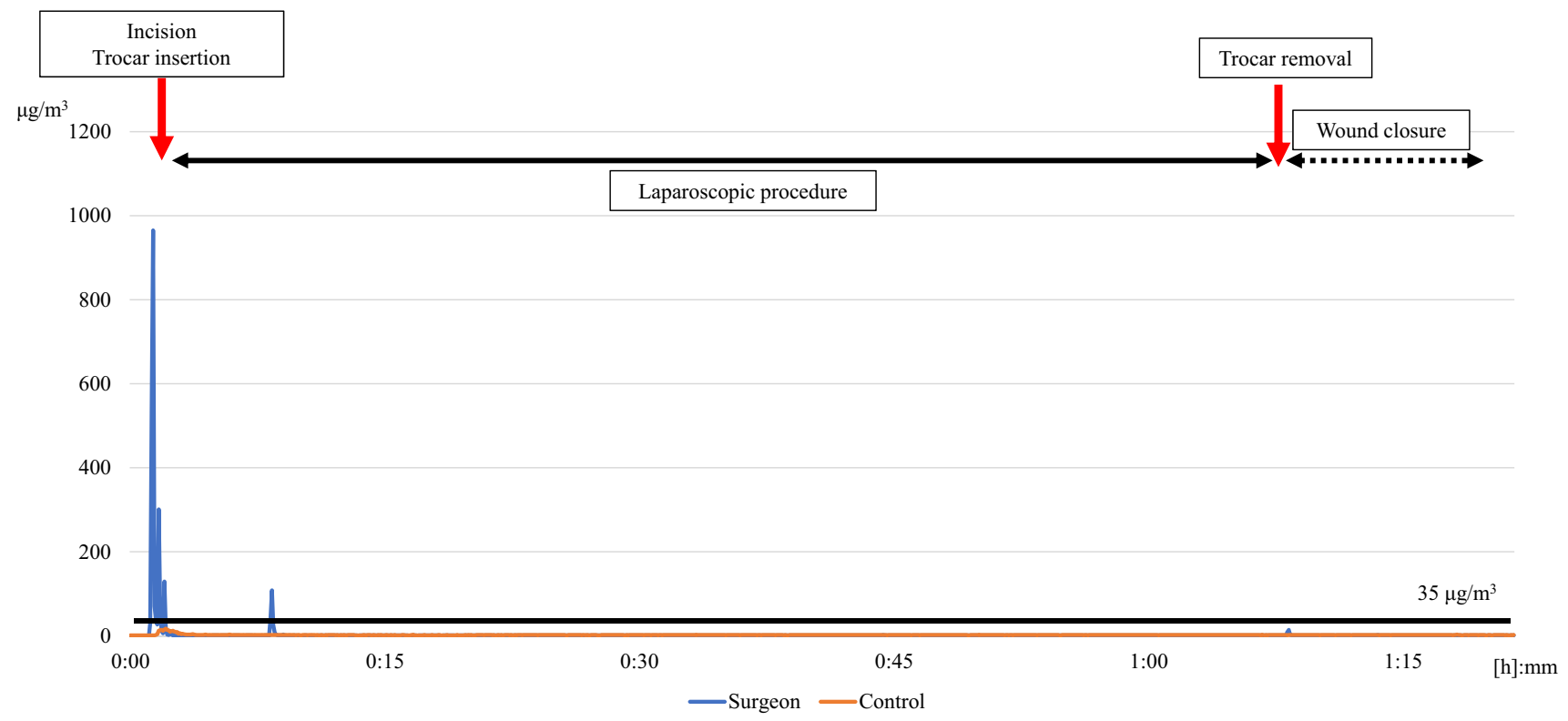

Fig. 3 Concentration of $\mathrm{PM}_{2.5}$ during transabdominal preperitoneal inguinal hernia repair (Patient 4). $P M_{2.5}$ particulate matter 2.5

been taken; however, in Japan, quicker responses to these recommendations were challenged by a delay in the installation of LEV systems.

$\mathrm{PM}_{2.5}$ is defined as suspended particulate matter in the air that is collected after filtering off large particles using a granulator, which separates particles with a $2.5 \mu \mathrm{m}$ diameter at a rate of 50\% [13]. In 2009, the Ministry of the Environment Government of Japan set the environmental standard for $\mathrm{PM}_{2.5}$ as an annual average value of $\leq 15 \mu \mathrm{g} /$ $\mathrm{m}^{3}$ and a daily average value of $\leq 35 \mu \mathrm{g} / \mathrm{m}^{3}$ [13]. In addition to respiratory diseases such as asthma and bronchitis [14], $\mathrm{PM}_{2.5}$ can increase the risk of cardiovascular disease [15] and impair cognitive function [16]. Our intraoperative measurements showed that $\mathrm{PM}_{2.5}$ could reach maximum levels of $1000 \mu \mathrm{g} / \mathrm{m}^{3}$, indicating that OR staff members, especially surgeons, are exposed to high concentrations of $\mathrm{PM}_{2.5}$ comparable to passive smoking, which is a health risk. Even if the $\mathrm{PM}_{2.5}$ level is within the standard range, 
(a)

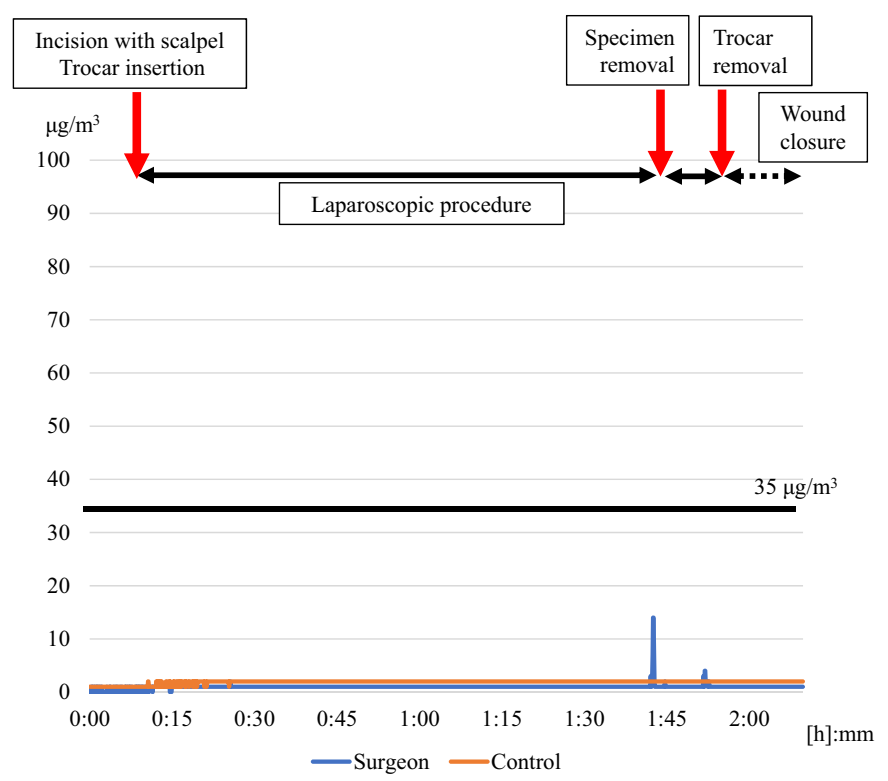

(b)

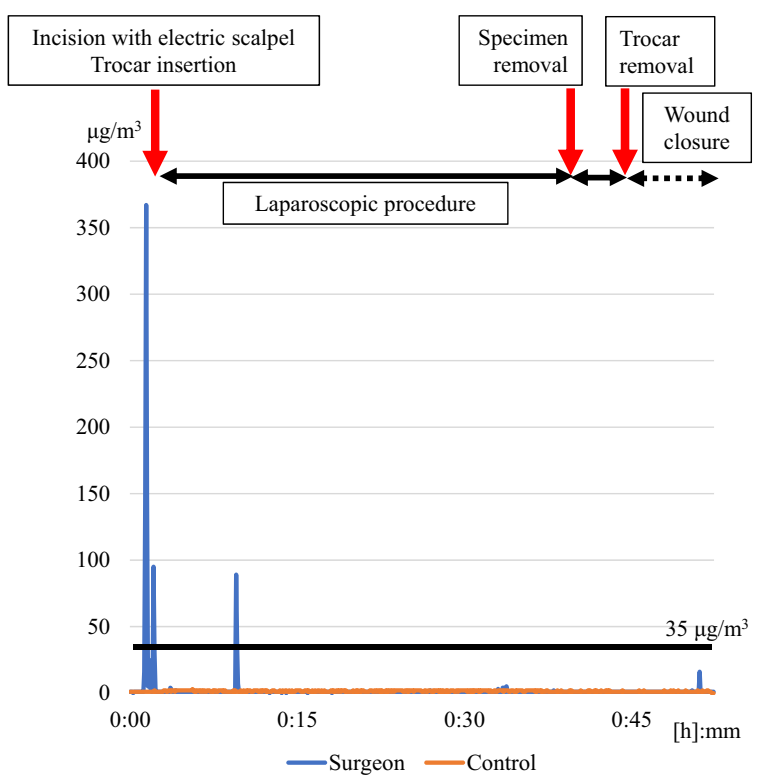

Fig. 4 Concentration of $\mathrm{PM}_{2.5}$ released during laparoscopic cholecystectomy. a Without electrocautery at the incision, almost no intraoperative increase in $\mathrm{PM}_{2.5}$ concentration was observed (Patient
7). b With electrocautery at the incision, a spiky elevation of $\mathrm{PM}_{2.5}$ occurred during the incision, but no elevation was observed during the intraperitoneal procedure (Patient 8 ). $P M_{2.5}$ particulate matter 2.5 (a)

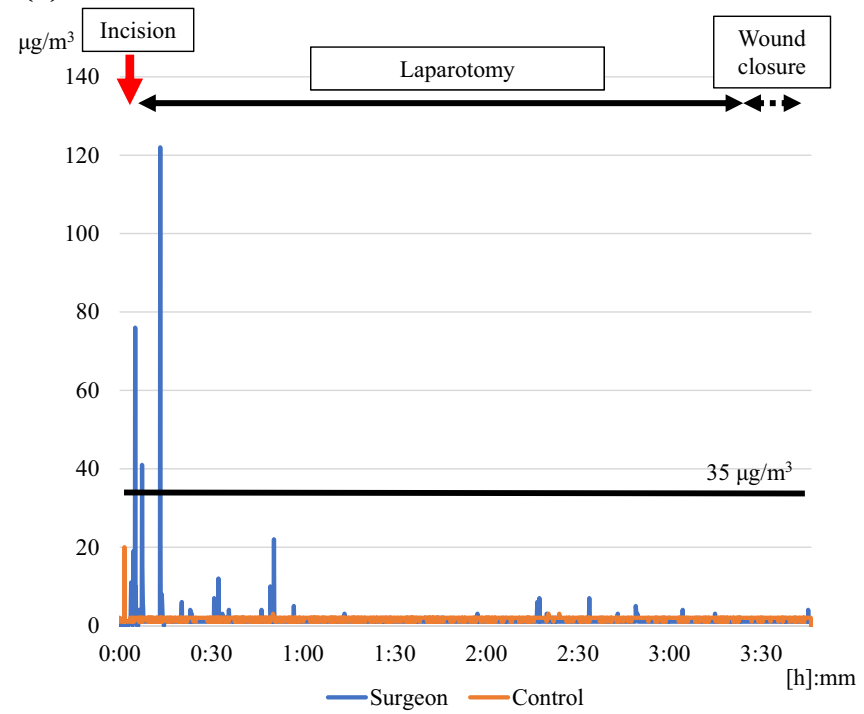

(b)

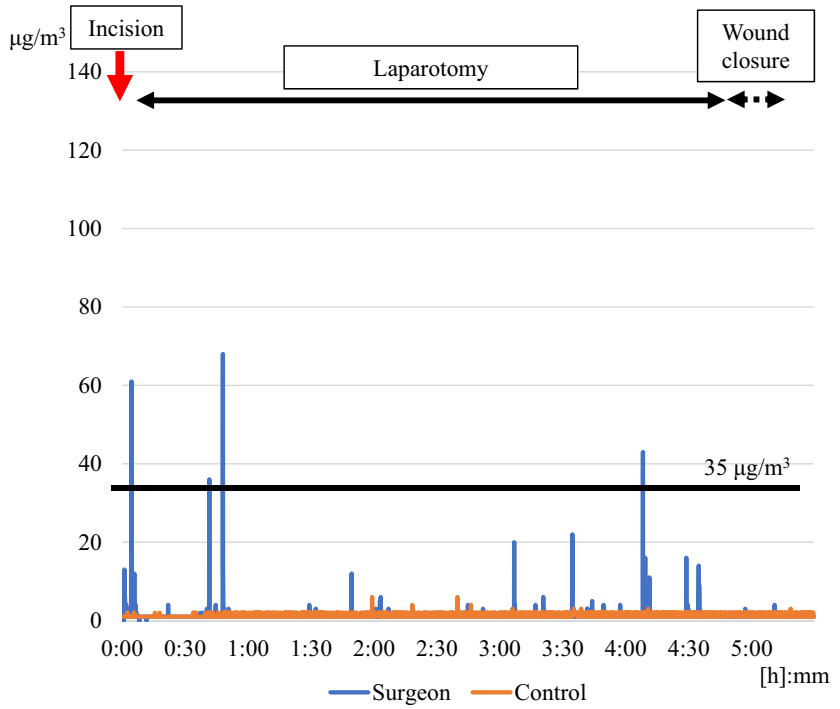

Fig. 5 Concentration of $\mathrm{PM}_{2.5}$ during laparotomy. a Total gastrectomy and cholecystectomy (Patient 13). b Distal pancreatectomy (Patient 14). During abdominal surgeries, only a modest increase in $\mathrm{PM}_{2.5}$ was observed. $P M_{2.5}$ particulate matter 2.5

a temporary sharp increase can become a risk factor for people with sensitivities, such as those with asthma. The present study could not evaluate the effects of different elements of $\mathrm{PM}_{2.5}$ in surgical smoke and air pollution; however, the adverse health effects of foreign substances absorbed into the lungs over a long period, triggering inflammatory reactions, are an important concern.
During mastectomy, skin flap elevation requires continuous electrocautery, leading to a high $\mathrm{PM}_{2.5}$ concentrations. It has been reported that the composition and concentration of surgical smoke may vary depending on the tissue composition [17]. Although electrocauterized incisions in fat do not produce more surgical smoke than those in other tissues $[18,19]$, the continuous use of electrocautery is required 
(a)

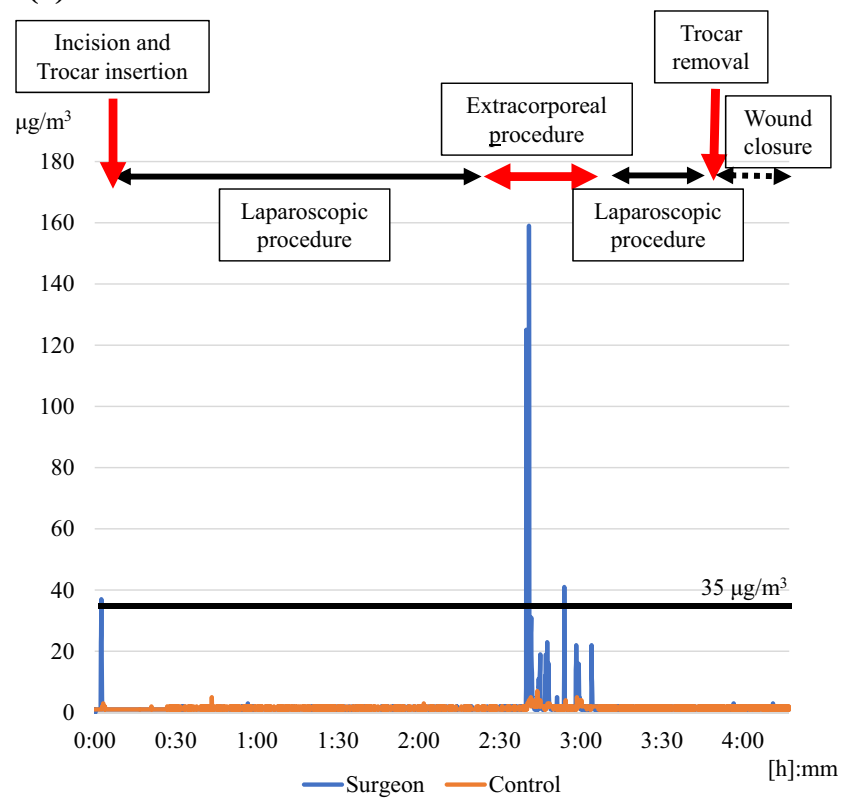

Fig. 6 Concentration of $\mathrm{PM}_{2.5}$ during laparoscopic colectomy. a Laparoscopic right colectomy (Patient 11). b Laparoscopic right colectomy (Patient 10). A remarkable elevation of $\mathrm{PM}_{2.5}$ in both surgeries

more in the breast than in gastrointestinal surgery. Another possible reason for the higher $\mathrm{PM}_{2.5}$ in mastectomy is that it is superficial surgery; therefore, the site of surgical smoke generation is closer to the measurement site than that in intra-abdominal surgeries. The duration of exposure to $\mathrm{PM}_{2.5}$ was shorter in laparoscopic surgery than in mastectomy, and limited to the wound incision and extracorporeal procedure (Figs. 3, 4a, 6). When only a scalpel was used for the wound incision without electrocautery (Fig. 4a), no elevation in $\mathrm{PM}_{2.5}$ was observed. However, surgeons should be careful while inserting and removing tools through the trocar and when insufflation gas leaks from the gap between the trocar and the skin [20].

The small number of cases analyzed in this study made it difficult to conclude how the OR area, room differential pressure, ISO class, and design ventilation frequency affected the $\mathrm{PM}_{2.5}$ concentration. However, surgical smoke is diffused upward by heat and reaches the mouth and nose area of the surgeon. In this study, the surgeon was exposed to high concentrations of $\mathrm{PM}_{2.5}$ in both ORs. As the ventilation system of the entire OR is far from the source of the generation of surgical smoke and the breathing areas (nose and mouth) of the surgeon, assistants, and scrub nurses, such a ventilation system alone cannot reduce the exposure of the OR staff to $\mathrm{PM}_{2.5}$. Surgical smoke can penetrate the gap between the mask and face of surgeons and OR staff, partly through the non-woven fabric, to reach the alveolar region and can cause respiratory diseases and systemic allergic reactions.

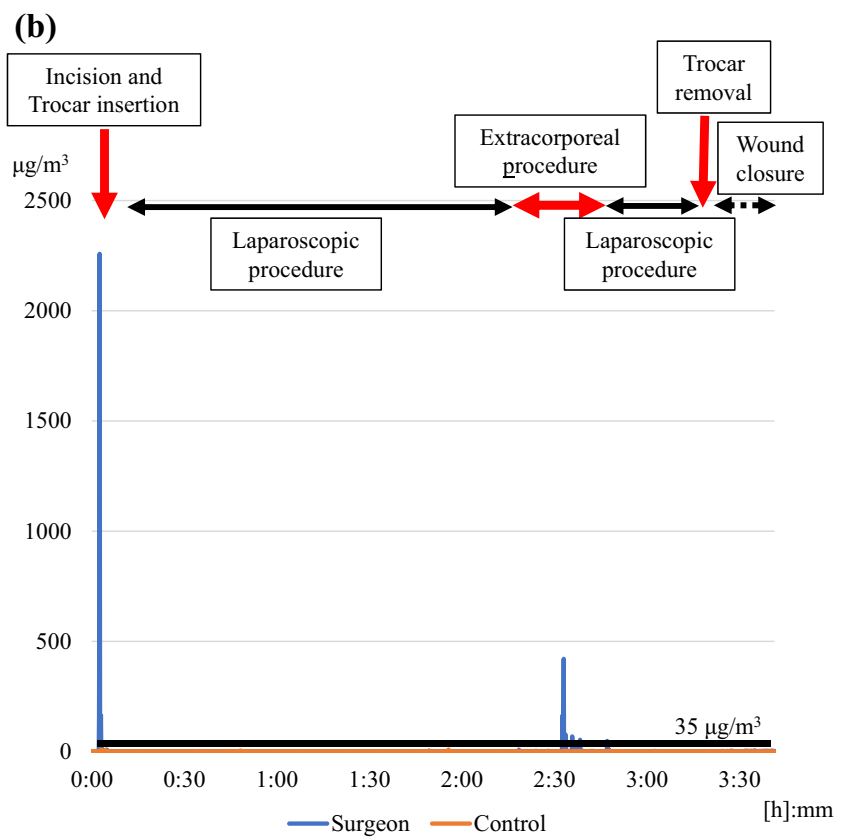

was observed during incision and extraperitoneal manipulation. $P M_{2.5}$ particulate matter 2.5

When this study was initiated, an LEV system had not been installed in the OR, so we measured the $\mathrm{PM}_{2.5}$ levels without it. However, because of the COVID-19 pandemic, we reduced the number of operations performed and suspended the $\mathrm{PM}_{2.5}$ measurements. When surgery resumed, LEV systems had been installed in our facility as a countermeasure against severe acute respiratory syndrome coronavirus two infections. These systems now accompany the use of energy devices.

Our study had two main limitations that should be addressed in future investigations. First, the sample size was small, and it was a single-center study. However, the findings confirmed the real-time $\mathrm{PM}_{2.5}$ concentration derived from surgical fields during various operations with the same equipment and surgeons before the incorporation of the LEV system in our institution. In the future, all ORs should be equipped with LEV systems and it may not be possible to measure the surgical smoke without LEV as we did in this study. Thus, this study may be the last to evaluate surgical smoke in the OR without an LEV system. Second, the $\mathrm{PM}_{2.5}$ concentration was measured on the surgeon's chest instead of around the mouth or nose. Sterile tubes were used for the measurements, which were disinfected and fixed to the surgeon's chest to prevent contamination of the surgical field in case of fixation removal. To measure $\mathrm{PM}_{2.5}$, we considered fixing the tube near the surgeon's mouth; however, we fixed it on the chest because we were concerned that it could fall and contaminate the surgical field, and also that if it was 
fixed on the neck it could distract the surgeon and affect the surgery. However, we measured the concentration of $\mathrm{PM}_{2.5}$ that the surgeons were directly exposed to intraoperatively, and the results suggested potential health risks.

In conclusion, this study showed that $\mathrm{PM}_{2.5}$ concentration increased rapidly with the intraoperative application of electrocautery, which may pose several health hazards to surgeons and the OR team. The management of surgical smoke is a serious concern and every medical institution, as an employer, has a responsibility to protect employees from surgical smoke by adopting appropriate measures. As surgeons, we hope that the LEV systems will enable us to effectively eliminate surgical smoke intraoperatively and perform surgical procedures without any interference. LEV systems should be improved based on feedback from surgeons about the effectiveness of the device.

Acknowledgements We thank Mr. Hirokazu Minomo for his support of the $\mathrm{PM}_{2.5}$ measurements during surgery and Dr. Junichi Masuda for his advice.

Author contributions $\mathrm{KO}, \mathrm{KH}, \mathrm{KK}, \mathrm{TM}, \mathrm{YN}, \mathrm{YT}, \mathrm{KY}, \mathrm{TN}, \mathrm{HM}$, and $\mathrm{HY}$ designed the study. $\mathrm{KO}, \mathrm{KH}$, and $\mathrm{KK}$ acquired the data. $\mathrm{KO}, \mathrm{TN}$, and $\mathrm{HY}$ analyzed the data. KO, KH, YN, YT, KY, HM, and HY interpreted the data. $\mathrm{KO}$ wrote the first draft of the manuscript. All authors read the drafted manuscript, provided feedback, and approved the final submitted version.

Funding There are no funding sources.

\section{Declarations}

Conflict of interest K.O. received an honorarium from Stryker Japan Inc., CONMED Japan Inc., Johnson \& Johnson Inc., and Meilleur Inc. T.H. received an honorarium from Japan Medicalnext Inc, Ltd. and Stryker Japan Inc. The funding source had no role in the design, practice, or analysis of this study. The remaining authors have no conflicts of interest to declare.

Ethical approval The study was approved by the Ethics Committee of Japan Baptist Hospital (Approval No. 19-11).

Informed consent Informed consent was obtained from all the patients enrolled in the study. All the procedures in the study were performed in accordance with the ethical standards laid down in the 1964 Declaration of Helsinki and its later amendments.

\section{References}

1. Okoshi K, Kobayashi K, Kinoshita K, Tomizawa Y, Hasegawa $\mathrm{S}$, Sakai Y. Health risks associated with exposure to surgical smoke for surgeons and operation room personnel. Surg Today. 2015;45:957-65.

2. Kwak HD, Kim SH, Seo YS, Song KJ. Detecting hepatitis B virus in surgical smoke emitted during laparoscopic surgery. Occup Environ Med. 2016;73:857-63.
3. Hallmo P, Naess O. Laryngeal papillomatosis with human papillomavirus DNA contracted by a laser surgeon. Eur Arch Otorhinolaryngol. 1991;248:425-7.

4. Calero L, Brusis T. Laryngeal papillomatosis-first recognition in Germany as an occupational disease in an operating room nurse. Laryngorhinootologie. 2003;82:790-3.

5. Rioux M, Garland A, Webster D, Reardon E. HPV positive tonsillar cancer in two laser surgeons: case reports. J Otolaryngol Head Neck Surg. 2013;42:54.

6. Zhou Q, Hu X, Zhou J, Zhao M, Zhu X, Zhu X. Human papillomavirus DNA in surgical smoke during cervical loop electrosurgical excision procedures and its impact on the surgeon. Cancer Manag Res. 2019;11:3643-54.

7. Ulmer BC. The hazards of surgical smoke. AORN J. 2008;87:721-34.

8. Aerosol consensus statement. Chest. 1991; 100:1106-9

9. Kwon JW, Park HW, Kim WJ, Kim MG, Lee SJ. Exposure to volatile organic compounds and airway inflammation. Environ Health. 2018;17:65.

10. Yamato H, Jiang Y, Ohta M. WHO Framework Convention on Tobacco Control (FCTC) Article 8: protection from exposure to tobacco smoke. Nihon Eiseigaku Zasshi. 2015;70:3-14.

11. Society of American Gastrointestinal and Endoscopic Surgeons, the European Association for Endoscopic Surgery. SAGES and EAES recommendations regarding surgical response to COVID19 crisis. 2020. https://www.sages.org/recommendations-surgi cal-response-covid-19/. Accessed 8 Dec 2021

12. The Japanese Medical Science Federation, Japan Surgical Society, the Japanese Society of Gastroenterological Surgery, the Japanese Association for Thoracic Surgery, the Japanese Society for Cardiovascular Surgery, the Japanese Society for Vascular Surgery, et al. Recommendations for surgical procedures in patients with positive or suspected novel coronavirus. Revised ed.; 2020. https://jp.jssoc.or.jp/modules/aboutus/index.php?content_id=53. Accessed 8 Dec 2021

13. Ministry of the Environment. Environmental standards for air pollution caused by fine particulate matter. 2009. https://www.env. go.jp/kijun/taiki4.html. Accessed 8 Dec 2021

14. Xing YF, Xu YH, Shi MH, Lian YX. The impact of PM2.5 on the human respiratory system. J Thorac Dis. 2016;8:E69-74.

15. Michikawa T, Ueda K, Takami A, Sugata S, Yoshino A, Nitta H, et al. Japanese nationwide study on the association between shortterm exposure to particulate matter and mortality. J Epidemiol. 2019;29:471-7.

16. Weuve J, Puett RC, Schwartz J, Yanosky JD, Laden F, Grodstein F. Exposure to particulate air pollution and cognitive decline in older women. Arch Intern Med. 2012;172:219-27.

17. Lin YW, Fan SZ, Chang KH, Huang CS, Tang CS. A novel inspection protocol to detect volatile compounds in breast surgery electrocautery smoke. J Formos Med Assoc. 2010;109:511-6.

18. Tan W, Zhu H, Zhang N, Dong D, Wang S, Ren F, et al. Characterization of the PM2.5 concentration in surgical smoke in different tissues during hemihepatectomy and protective measures. Environ Toxicol Pharmacol. 2019;72:103248.

19. Karjalainen M, Kontunen A, Saari S, Rönkkö T, Lekkala J, Roine A, et al. The characterization of surgical smoke from various tissues and its implications for occupational safety. PLoS ONE. 2018;13:e0195274.

20. Cahill RA, Dalli J, Khan M, Flood M, Nolan K. Solving the problems of gas leakage at laparoscopy. Br J Surg. 2020;107:1401-5.

Publisher's Note Springer Nature remains neutral with regard to jurisdictional claims in published maps and institutional affiliations. 